УДК 004.932.72’1

\title{
АВТОМАТИЗИРОВАННАЯ СИСТЕМА ДЕТЕКТИРОВАНИЯ ВОЛН ОСБОРНА НА ОСНОВЕ ВЕЙВЛЕТ-ПРИЗНАКОВ И НЕЙРОННОЙ СЕТИ
}

\author{
А. А. БОРОДИН, Н. А. БОРОДИН, А. Н. ДОНЧИЛО \\ ЧП Мир Инженерных Решений, \\ Украина, Одесса, 65005, ул. Мельницкая, 26/2
}

\begin{abstract}
Аннотация. Разработана автоматизированная система детектирования волн Осборна, которая отличается чувствительностью 94,63\% и точностью классификации 94,58\% волн типов «notch» и «slur» в составе кардиосигнала. Применены метод квазисогласованной вейвлет-фильтрации и метод главных компонент для выделения и формирования векторов-признаков, являющихся входными данными классификатора. В качестве классификатора использована нейронная сеть прямого распространения ошибки с топологией многослойного персептрона. Для обучения, тестирования и проверки нейронной сети использованы выборки сигналов, построенные на основе данных открытой базы медицинских сигналов PhysioNet. B paботе использованы 12-канальные электрокардиограммы 60-ти здоровых пациентов в возрасте 17-87 лет, на основе которых сформирована база данных из 14832 сигналов (9888 сигналов с волной Осборна двух типов и 4944 без патологии). Предложенный подход обеспечил точность классификации, превышающую точность известных методов.
\end{abstract}

Ключевые слова: волны Осборна; ЭКГ сигнал; вейвлет-признак; квазисогласованная вейвлет фильтрация; метод главных компонент; нейронная сеть прямого распространения ошибки; обучение нейронной сети; МГК; ДВП

\section{АКТУАЛЬНОСТЬ ПРОБЛЕМЫ}

Волна или зубец Осборна, известная также как J-wave, представляет собой хорошо выраженный высокочастотный положительный всплеск амплитуды сигнала электрокардиограммы (ЭКГ), следующий за комплексом QRS, или небольшой добавочный всплеск на нисходящем сегменте зубца $R[1]$. Амплитуда волны Осборна составляет как минимум 0,1 мВ, а длительность - около 20 мс [2].

Обнаружение и правильное объяснение изменений на ЭКГ в виде волны Осборна является важным аспектом клинической практики, т.к. появление этого артефакта связано с критическим состоянием пациента и фатальным исходом. В связи с тем, что указанная патоло- гия встречается довольно редко, врачи могут просто не иметь достаточно практических навыков ее выявления и классификации, поэтому разработка надежной системы автоматического детектирования волны Осборна является актуальной проблемой.

\section{СУЩЕСТВУЮЩИЕ РЕШЕНИЯ}

В [3] разработан метод обнаружения волн Осборна на основе определения точки окончания QRS комплекса на его последнем нисходящем участке. Достигнута высокая точность и чувствительность предложенного метода $(93,0$ и 90,5\%). Однако полученные результаты требуют дополнительной доработки, т.к. в работе рассмотрено только 100 сигналов ЭКГ 12 элек- 


\section{БИБЛИОГРАФИЧЕСКИЙ СПИСОК}

1. Junttila, M. J.; Sager, S. J.; Tikkanen, J. T.; Anttonen, O.; Huikuri, H. V.; Myerburg, R. J. "Clinical significance of variants of J-points and J-waves: early repolarization patterns and risk," Eur. Heart J., Vol. 33, No. 21, P. 2639-2643, 2012. DOI: 10.1093/eurheartj/ ehs110.

2. Yuanhui, P.; Jielin, P. "J wave syndrome," Advances in Cardiovascular Diseases, Vol. 32, No. 4, P. 483-486, 2011.

3. Clark, E. N.; Katibi, I.; Macfarlane, P. W. "Automatic detection of end QRS notching or slurring," $J$. Electrocardiol., Vol. 47, No. 2, P. 151-154, 2014. DOI: 10.1016/j.jelectrocard.2013.10.007.

4. Wang, Y. G.; Wu, H. T.; Daubechies, I.; Li, Y.; Estes, E. H.; Soliman, E. Z. "Automated J wave detection from digital 12-lead electrocardiogram," J. Electrocardiol., Vol. 48, No. 1, P. 21-28, 2015. DOI: 10.1016/j.jelectro card.2014.10.006.

5. Li, Dengao; Bai, Yanfei; Zhao, Jumin. "A method for automated J wave detection and characterization based on feature extraction," Lect. Notes Comput. Sci., Vol. 9196, P. 421-433, 2015.

6. Рабинер, Л.; Гоулд, Б. Теория и применение ичирровой обработки сигналов. М.: Мир, 1978. 848 с.

7. Goldberger, A. L.; Amaral, Luis A. N.; Glass, L.; Hausdorff, J. M.; Ivanov, P. Ch.; Mark, R. G.; Mietus, J. E.; Moody, G. B.; Peng, Chung-Kang; Stanley, H. E. "PhysioBank, PhysioToolkit and PhysioNet: Components of a new research resource for complex physiologic signa1s," Circulation, Vol. 101, No. 23, P. e215-e220. 2000. DOI: $10.1161 / 01 . C I R .101 .23 . e 215$.

8. De la Rosa, E.; Fernandez, E. A. "Spectral bands analysis of ECG derived signals in Chagasic patients," Proc. of VI Latin American Congress on Biomedical Engineering CLAIB 2014, 29-31 Oct. 2014, Paraná, Argentina. Springer, 2014, Vol. 49, pp. 484-487. DOI: 10.1007/978-3-319-13117-7 124.

9. Бородин, А.А. "Квазисогласованная вейвлет-фильтрация," Известия вузов. Радиэлектроника, T. 54, № 3, C. 22-29, 2011. URI: http://radio.kpi.ua/ article/view/S0021347011030034.

10. Дъяконов, В.П. Вейвлеты. От теории к практике. М.: СОЛОН, 2002. 448 с.

11. Айвазян, С.А.; Бухштабер, В.М.; Енюков, И.С.; Мешалкин, Л.Д. Прикладная статистика. Классификация и снижение размерности. М.: Финансы и статистика, 1989. 607 с. 
12. Masters, Timothy. Practical Neural Network

Recipes in C++. San Diego, CA.: Academic Press, 1993.

$493 \mathrm{c}$.

Поступила в редакцию 01.03.2017

После переработки 05.03.2018 